\title{
Fragile egos
}

\author{
Stephen B Hanauer
}

We get a great deal of kudos as clinicians. Caring for individuals on a day-to-day basis is the most rewarding component of a career in medicine. Frankly, however, it is not often that we receive sufficient gratitude for our daily and ongoing efforts. On the uncommon occasions that our expertise and compassion are acknowledged, we typically take the praise in our stride and move on to the next clinical situation. By contrast, when things go wrong our emotional shell is quickly cracked. One gracious compliment and it's 'no big deal', whereas one mistake and we are crushed.

I recently had this experience. After performing thousands of uncomplicated surveillance colonoscopies, one of my patients developed a colonic perforation. The examination was as routine as routine can be. The patient and I chatted throughout her sedation, the procedure went easily and her initial recovery was uneventful - that is, until 8 hours later when the patient's family called to describe her ominous shoulder discomfort that progressed to disabling abdominal pain and a distended belly. To add to the dilemma the patient was already at home, 25 miles from our hospital. Emergencyroom evaluation at her local facility led to a CT scan, during which free intraperitoneal air was detected, and the patient underwent exploratory surgery and a diverting sigmoid colostomy with a Hartmann pouch.

One's healing prowess quickly deteriorates to a sense of impotence when a patient suffers ...the caring physician or surgeon ... must remain humble in the face of the diseases, therapies and procedures ... lest we face unexpected outcomes or, worse, cause harm

SB Hanauer is Editorin-Chief of Nature Clinical Practice Gastroenterology \& Hepatology.

\section{Competing interests}

The author declared he has no competing interests.

www.nature.com/clinicalpractice doi:10.1038/ncpgasthep0714 a complication that is out of both one's control and physical presence. Indeed, telephone communications with the local emergencyroom physicians and on-call surgeon who were required to take charge of my patient and to work through the night were humbling, at best. Communications with the patient's family were, similarly, apologetic yet optimistic.

Events such as these make the concept of 'routine' too glib. We are raised on the premise of "primum non nocere" and are not accustomed to causing harm. In addition, as we go through the process of obtaining informed consent the very real potential for complications is, too often, minimized in our own minds. Our egos are too large to anticipate or accept the rare events that affect us all ... until they happen. These events expose us to the ooze of our fallibility and insecurities. These one-in-a-thousand casualties to our patients and our egos have a far bigger impact than the 999 positive effects we have on a regular basis.

So be it. There is no such thing as a routine procedure. As I was informed by my father (who is not a physician), the definition of a minor operation is "an operation on someone else." However, the caring physician or surgeon, while empathizing with a patient and their family, must remain humble in the face of the diseases, therapies and procedures that we attempt to improve, heal or cure, lest we face unexpected outcomes or, worse, cause harm. 